\title{
A climatology of the F-layer equivalent winds derived from ionosonde measurements over two decades along the $120^{\circ}-150^{\circ} \mathrm{E}$ sector
}

\author{
X. Luan ${ }^{1,2,3}$, L. Liu ${ }^{1}$, W. Wan ${ }^{1}$, J. Lei ${ }^{1,2,3}$, and T. Yu ${ }^{1}$ \\ ${ }^{1}$ Institute of Geology and Geophysics, CAS, Beijing 100029, China \\ ${ }^{2}$ Wuhan Institute of Physics and Mathematics, CAS, Wuhan 430071, China \\ ${ }^{3}$ Graduate School of the Chinese Ascademy of Sciences, Beijing, China
}

Received: 11 July 2003 - Revised: 29 March 2004 - Accepted: 5 May 2004 - Published: 7 September 2004

\begin{abstract}
The vertical equivalent winds (VEWs) at the F-layer are analyzed along the $120^{\circ}-150^{\circ} \mathrm{E}$ longitude sector with an emphasis on their latitudinal dependence. The VEWs are derived from the monthly median data of fourteen ionosonde stations over two decades. The results show that the VEWs have considerable dependences on the magnetic latitude with an approximate symmetry about the magnetic equator. They are mostly controlled by the electric field drifts in the magnetic equatorial region, and shift to be mostly contributed by neutral winds at mid-latitudes. The relative contribution of the two dynamic factors is regulated by the magnetic dip in addition to their own magnitudes. The VEWs generally have opposite directions and different magnitudes between lower and higher latitudes. At solar minimum, the magnitudes of VEWs are only between -20 and $20 \mathrm{~m} / \mathrm{s}$ at lower latitudes, while at higher latitudes they tend to increase with latitudes, typically having magnitudes between $20-40 \mathrm{~m} / \mathrm{s}$. At solar maximum, the VEWs are reduced by about $10-20 \mathrm{~m} / \mathrm{s}$ in magnitudes during some local times at higher latitudes. A tidal analysis reveals that the relative importance of major tidal components is also different between lower and higher latitudes.

The VEWs also depend on local time, season and solar activity. At higher latitudes, the nighttime VEWs have larger magnitude during post-midnight hours and so do the daytime ones before midday. The VEWs tend to have an inverse relationship with solar activity not only at night, but also by day, which is different from the meridional winds predicted by the HWM93 model. The latitudinal dependence of VEWs has two prevailing trends: one is a maximum at the highest latitudes (as far as the latitudes concerned in the present work); the other is a mid-latitude maximum. These two latitudinal trends are mostly dependent on season, while they depend relatively weakly on local time and solar activity. The latitudinal gradients of VEWs also show a tendency of a mid-
\end{abstract}

Correspondence to: L. Liu

(liul@mail.igcas.ac.cn) latitude maximum, except that there are much stronger latitudinal gradients at southern higher mid-latitudes in some seasons. The gradients during daytime are much smaller at solar maximum than minimum, whereas they are generally comparable at night under both solar activity levels.

Key words. Meteorology and atmospheric dynamics (thermospheric dynamics, meridional wind, electric field drift, equivalent winds)

\section{Introduction}

Recently, the climatology of thermospheric dynamics has been extensively investigated with the measurements of Fabry-Perot interferometer (FPI), incoherent scatter radar (ISR) and ionosonde (e.g. Buonsanto, 1990; Hagan, 1993; Biondi et al., 1999; Igi et al., 1999; Buonsanto and Witasse, 1999; Kawamura et al., 2000; Emmert et al., 2003; Foppiano et al., 2003). Up to now, some climatological models of the thermospheric horizontal winds (e.g. Hedin et al., 1996; Miller et al., 1997) and electric field drifts (Scherliess and Fejer, 1999; Zhang et al., 2001) have been developed. The study of the thermospheric dynamics is not only required for information on the general thermospheric circulation but also necessary as an important reference for identifying effects under disturbed conditions (Miller et al., 1993; Fejer et al., 2002).

The basic characteristics of thermospheric dynamics have been well known at low and higher latitudes. At low latitudes, electric fields play an important role in the $\mathrm{F}$ region dynamics. A significant feature of equatorial electric field drifts is the pre-reversal enhancement during solar maximum years, while this enhancement is either greatly reduced or completely absent during solar minimum years (Scherliess and Fejer, 1999). The meridional winds at mid-latitude are consistent with the solar EUV forcing and the consequent latitudinal pressure gradients, namely poleward by day and 
equatorward at night (Hagan, 1993; Kawamura et al., 2000). At higher mid-latitudes, the meridional winds can be influenced by the aurorally driven high-latitude circulation cell even under quiet conditions (Hagan, 1993; Emmert et al., 2003).

The thermospheric dynamics depends on both latitude and longitude, and changes with local time, season, and solar activity. Detailed latitudinal trends of meridional winds are involved in the above climatological works (e.g. Miller et al., 1997; Biondi et al., 1999; Emmert et al., 2003; Foppiano et al., 2003) and other investigations (Salah et al., 1987; Oliver et al., 1988; Wickwar, 1989; Miller et al., 1993; Zhang et al., 1995). Miller et al. (1997) have presented climatology of the F-layer meridional equivalent winds at various stations. Those previous results show that the meridional winds are generally larger at higher latitudes and their diurnal amplitudes increase with latitude, and also present a strong dependence of the latitudinal variations on local time, season and solar activity. However, most of those works either concentrate on only few stations or deal with only a short time period. The climatology of the thermospheric dynamics derived with a uniform method and database over a much broader latitudinal range is very limited.

In this work, we try to present the climatology of the vertical components of equivalent winds (VEWs) with a systemic analysis of their latitudinal dependence over a long period. The VEWs combine both the contributions of $\boldsymbol{E} \times \boldsymbol{B}$ drifts and meridional winds. The great differences between the vertical components of equivalent winds (VEWs) and the meridional ones are that the vertical ones are more controlled by electric field drifts at low latitudes and greatly affected by the magnetic inclination at higher latitudes, although both components of the equivalents are regulated by meridional winds. The basic characteristics and solar activity variation of VEWs over Wuhan $\left(114.4^{\circ} \mathrm{E}, 30.6^{\circ} \mathrm{N}\right.$, Magnetic $\left.20^{\circ} \mathrm{N}\right)$ have been discussed by Liu et al. (2003a, b, c) in detail. Over Wuhan, the VEWs are generally downward by day and upward at night with predominant diurnal and semidiurnal components, and driven by neutral winds more than by electric field drifts (Liu et al., 2003a, b). The VEWs are larger upward in summer, larger downward in winter, and show an equinox asymmetry at higher solar activity conditions (Liu et al., 2003a). They tend to decrease with the increase of solar activity both by midday and at midnight, and the daytime trend has a prominent seasonal dependence (Liu et al., 2003c).

The method of Liu et al. (2003b) is very convenient and fast to derive VEWs from ionosonde measurements. In the present work, ionosonde measurements with a much expanded latitudinal distribution over a long period are used. We deal with the VEWs at magnetic latitudes between $51.2^{\circ} \mathrm{S}-51.5^{\circ} \mathrm{N}$ along the $120^{\circ}-150^{\circ} \mathrm{E}$ longitude sector. The VEWs at solar minimum and maximum, and their tidal components at solar minimum, are analyzed with an emphasis on their latitudinal dependence. In addition, the VEWs are compared with the similar components estimated from the empirical HWM93 model (Hedin et al., 1996) and the electric field drift model (Scherliess and Fejer, 1999). The results are also contrasted with previous works involving the F-layer drifts and meridional winds.

\section{Method and data selection}

The method for deriving the VEWs from the F-layer peak height $(h m \mathrm{~F} 2)$ and critical frequency $(f o \mathrm{~F} 2)$ has been introduced by Liu et al. (2003b) in detail and applied to discuss the seasonal and solar cycle variations over Wuhan (Liu et al., 2003a, c). This method adopted the following assumption (Rishbeth et al., 1978): (1) The topside profile can be described by a function (usually assumed to keep a constant form, for example a Chapman layer); (2) The $F_{2}$ layer peak is well above the photoionization production peak; (3) Above the F-layer peak, the dominant ion is $\mathrm{O}^{+}$and decays mainly though reactions with $\mathrm{O}_{2}$ and $\mathrm{N}_{2}$. The VEWs express as Eq. (1)

$$
\begin{aligned}
W= & \frac{d h_{m}}{d t}+(a-1) \frac{q_{m} H}{N_{m}}+\left(a_{O_{2}}^{\prime}-a c_{O_{2}}\right) \beta_{O_{2}} H \\
& +\left(a_{N_{2}}^{\prime}-a c_{N_{2}}\right) \beta_{N_{2}} H+W_{d} \sin ^{2} I,
\end{aligned}
$$

where the suffix m denotes the value at the peak height; $h_{m}$, $N_{m}$ and $q_{m}$ are the F2-layer peak height, maximum electron density and ion production rate at the peak height, respectively. $W_{d}$ is the diffusion velocity; $I$, the magnetic dip; $c_{\mathrm{O}_{2}}$ and $c_{N_{2}}$, the servo constants; $H$, the scale height of neutral $\mathrm{O}$ atom; $a$, the factor of the topside profile; $a_{\mathrm{O}_{2}}^{\prime}$ and $a_{\mathrm{N}_{2}}^{\prime}$, the height integral constants. $W$ is the vertical equivalent wind (VEW), combining both the effects of neutral meridional winds $(U)$ and $\boldsymbol{E}_{\text {east }} \times \boldsymbol{B}$ drifts $\left(V_{N \perp}\right)$, as follows:

$W=U \sin I \cos I+V_{N \perp} \cos I$.

A profile function of the topside ionosphere and the constant $c$ are needed to derive the VEWs. In this work the topside electron profiles are assumed as a Chapman layer. According to the discussion of Buonsanto et al. (1997), we multiply the constant $c$ introduced from Rishbeth (1967) by a factor of 0.75 and smooth them during the transition time between day and night. The cross section of $\mathrm{O}^{+}-\mathrm{O}$ collision takes the formula of Pesnell et al. (1993). The calculation of neutral and ion density and temperature follows the description of Liu et al. (2003a). The F2 layer peak height is deduced from the hourly median values of $\mathrm{M} 3000 \mathrm{~F} 2, f o \mathrm{~F} 2$ and $f o \mathrm{E}$ with the empirical relationship proposed by Dudency (1983); $f o \mathrm{E}$ was calculated with a modified version of the CCIR formula (Buonsanto and Titheridge, 1987) if not observed.

Data included in this work are from the two CD-ROMs of Ionospheric Digital Database published by the U.S. National Geophysics Data Center (NGDC) in Boulder, Colorado. The CD-ROMs include global ionosonde measurements from 1957 to 1990 . The measurements of fourteen ionosonde stations over 22 years are carefully selected. These stations have a good latitudinal distribution along the $120^{\circ}-150^{\circ} \mathrm{E}$ longitude sector, in which some parts of the East Asia sector 
Table 1. The ionosonde stations and years analyzed.

\begin{tabular}{lrrrrrr}
\hline \multicolumn{1}{c}{ Station } & \multicolumn{2}{c}{ Geographic } & \multicolumn{2}{c}{ Geomagnetic } & DIP & Years analyzed \\
& Lat. & Long. & Lat. & Long. & & \\
\hline Hobart & -42.9 & 147.3 & -51.2 & 224.9 & -72.4 & $1957-1990$ \\
Canberra & -35.3 & 149.1 & -43.5 & 225.0 & -65.7 & $1957-1990$ \\
Brisbane & -27.5 & 152.9 & -35.3 & 227.5 & -57.3 & $1957-1986$ \\
Townsville & -19.7 & 146.9 & -28.4 & 219.7 & -48.6 & $1961-1990$ \\
Vanimo & -2.7 & 141.3 & -12.1 & 211.8 & -20.8 & $1967-1990$ \\
Manila & 14.7 & 121.1 & 3.9 & 190.6 & 13.9 & $1964-1989$ \\
Taipei & 25.0 & 121.2 & 14.2 & 190.3 & 34.3 & $1959-1989$ \\
Okinawa & 26.3 & 127.8 & 15.8 & 196.4 & 36.4 & $1957-1988$ \\
Yamagawa & 31.2 & 130.6 & 20.8 & 198.6 & 43.8 & $1957-1990$ \\
Kokubunji & 35.7 & 139.5 & 26.0 & 206.2 & 48.7 & $1957-1990$ \\
Akita & 39.7 & 140.1 & 30.0 & 206.3 & 53.3 & $1957-1989$ \\
Wakkanai & 45.4 & 141.7 & 35.8 & 206.9 & 59.1 & $1957-1988$ \\
Khabarovsk & 48.5 & 135.1 & 38.4 & 200.8 & 63.2 & $1959-1990$ \\
Yakutsk & 62.0 & 129.6 & 51.5 & 194.5 & 75.4 & $1957-1990$ \\
\hline
\end{tabular}

are included, as presented in Table 1. The data are binned according to the solar activity level, month and local time at each station. We define periods with the monthly mean solar $10.7 \mathrm{~cm}$ flux index (F107) less and greater than 120 as solar minimum and maximum, respectively. It is a pity that the observations of the southern higher mid-latitude station, Hobart, are often absent during some hours in June and September at solar minimum and we cannot obtain full-day data from Hobart during these two months.

This analysis neglects the possible longitudinal dependence. The HWM93 model predicts little longitudinal variations of the meridional winds except for high latitudes (Titheridge, 1995b). According to the work of Karpachev et al. (2001), the longitudinal variation of vertical plasma drifts induced by neutral winds at the $120^{\circ}-150^{\circ} \mathrm{E}$ sector is less than $10 \mathrm{~m} / \mathrm{s}$ at mid-latitudes when meridional winds are large enough. There are also possible errors from the uncertainty of atomic oxygen density from the MSIS model (Hedin, 1987), and the effect of magnetic activity can not be eliminated completely by using the monthly median data. In addition, peak heights derived from ionospheric data $(\mathrm{M} 3000 \mathrm{~F} 2$, $f o \mathrm{~F} 2$ and $f o \mathrm{E}$ ) have a typical uncertainty of $10-20 \mathrm{~km}$, giving an overall error of about $40 \mathrm{~m} / \mathrm{s}$ in meridional winds (Titheridge, 1995a), which indicates this error is no more than $20 \mathrm{~m} / \mathrm{s}$ around mid-latitudes and much smaller at other latitudes, considering the dependence of VEWs on the magnetic inclination. However, since the above errors are random and the ionosphere data are routinely observed for a long period, the total errors may be much smaller.

\section{Results}

Generally, the eastward electric fields or equatorward meridional winds contribute to the upward VEWs, while the westward electric field or poleward meridional winds tend to induce downward VEWs (Eq. (2)). As can be seen from Eq. (2), the VEWs may be more controlled by electric field at low latitudes where the magnetic inclination is small, and as expected, the VEWs can be considered as neutral winds at mid-latitude, where the contribution of zonal electric field can be neglected (Miller et al., 1997). If not specified, the latitude mentioned refers to magnetic latitude in the following.

\subsection{The averaged diurnal pattern}

Figure 1 presents the averaged diurnal and latitudinal variation of VEWs during solar minimum years in all seasons along the $120^{\circ}-150^{\circ} \mathrm{E}$ longitude sector. The VEWs are approximately symmetrical about the magnetic equator and their magnitudes show a strong dependence on magnetic latitude. At higher latitudes, they blow upward at night and downward by day and the magnitudes tend to increase with latitudes during both nighttime and daytime. The transition time between the upward and downward VEWs is at about 05:00-07:00 LT in the morning and at about 17:00-19:00 LT in the evening. At lower latitudes (typically lower than about $10^{\circ}$ ), the directions of VEWs are generally opposite, namely downward at night and upward by day. The time intervals of the upward VEWs are much shorter than the downward. The magnitudes of VEWs are small, no more than $20 \mathrm{~m} / \mathrm{s}$, in general. At higher latitudes, the VEWs' magnitudes are typically about $20-40 \mathrm{~m} / \mathrm{s}$, both by day and at night. The 


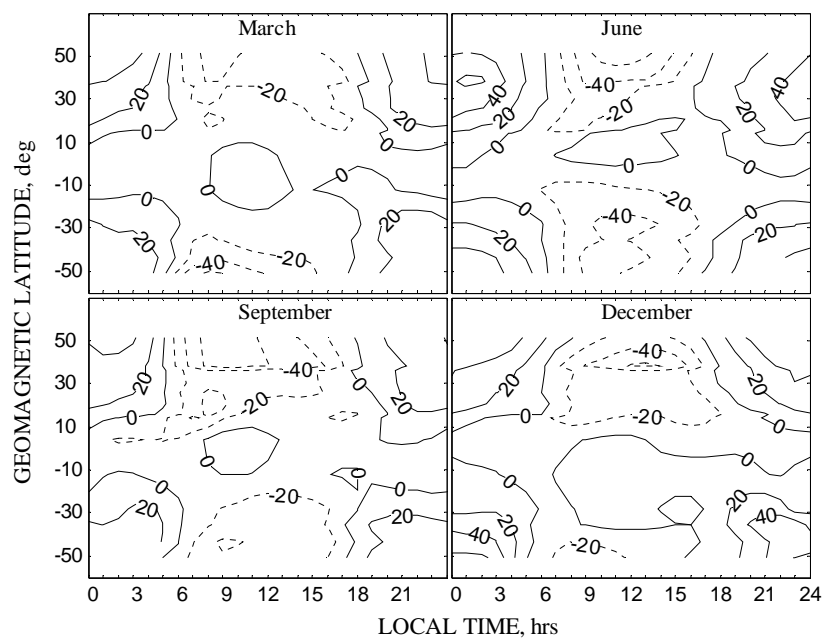

Fig. 1. The averaged diurnal and latitudinal variation of the vertical equivalent winds (VEWs) in each season for solar minimum. Positive upward.

differences in direction and magnitude of the VEWs between low and higher latitudes are essentially due to the different major dynamical controls, which will be discussed in detail at the Manila and Wakkanai stations (Sect. 4.1).

Figure 2 depicts the averaged diurnal and latitudinal variation of VEWs at solar maximum. The behaviors of VEWs are similar to those of solar minimum, but at higher latitudes their magnitudes are reduced by about $20 \mathrm{~m} / \mathrm{s}$ at some local times, both by day and at night. The detailed comparison of VEWs at particular local hours under two solar activity levels is presented in Sects. 3.3 and 3.4.

\subsection{The seasonal variation}

The VEWs at the two hemispheres tend to be symmetrical about the magnetic equator. However, the extent of the symmetry is relatively better during equinox than solstice periods and by night than during daytime. Seen from Figs. 1 and 2, the nighttime VEWs generally have a good symmetry about the magnetic equator, except that the VEWs are a little stronger in the summer hemisphere (northern June or southern December) than in the winter one (northern December or southern June) after midnight. In contrast, the great asymmetry of daytime VEWs at the two hemispheres is evident in all seasons.

Firstly, it is obvious that, during solstice months, the daytime upward VEWs at lower latitudes depart away from the magnetic equator where they lie during the equinox period, and intrude into the summer hemisphere (Figs. 1 and 2). It can be well explained by the transequatorial meridional winds from the summer to the winter hemisphere (Chan and Walker, 1984), since the empirical electric field drift model predicts no obvious daytime magnitudes variation of the electric field drifts from summer to winter (Scherliess and Fejer, 1999). Balan et al. (1995) also reported that the movements of ionization controlled by the electric fields at low lat-

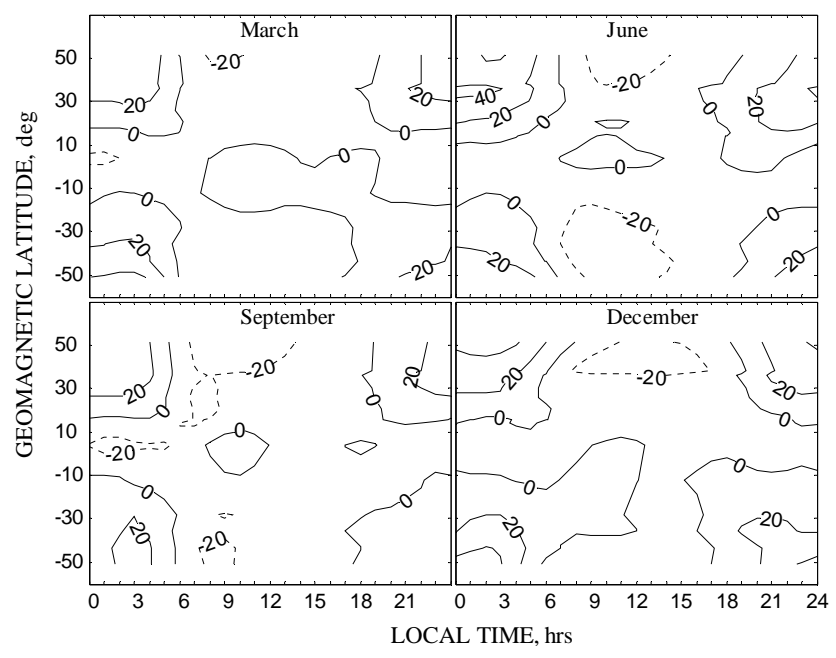

Fig. 2. Same as Fig. 1, but for solar maximum.

itudes are similar at both hemispheres, and that the magnetic meridional winds can lead to significant differences between two hemispheres. The flow from summer to winter hemisphere is just an equatorward flow at the summer hemisphere and a poleward one at the winter hemisphere, which contributes to the upward and downward VEWs, respectively.

Secondly, at latitudes higher than about $30^{\circ}$ the daytime VEWs are always larger in magnitudes in the Northern Hemisphere than the Southern Hemisphere, except during the March equinox, and at latitudes between about $10^{\circ}$ and $30^{\circ}$, the northern daytime VEWs magnitudes are also larger, except in June (Fig. 1). It is distinct that the northern daytime VEWs' magnitudes are much larger than the southern ones during September and December. The similar feature of large daytime magnitudes of VEWs and meridional equivalent winds during fall and winter were also reported at Wuhan (Liu et al., 2003a) and Kokubunji (Igi et al., 1999), respectively.

Besides the effect of apparent transequatorial meridional winds during the solstice period, the discrepancy of geographical latitudes between the two hemispheres may be partly responsible for the great asymmetry of daytime VEWs. Because of the displacement of the geographical equator from the geomagnetic one at this longitude sector, at the same magnetic latitude in two hemispheres, the southern ones are closer to the geographical equator. This proximity makes the southern magnetic latitudes lie at lower geographical latitudes than the northern ones. Hence, the two hemispheres divided by magnetic equator may absorb different solar heat in-site even during equinox periods. On the other hand, if the daytime VEWs tend to increase with geographic latitude, it will be reasonable that the daytime VEWs are generally larger in the Northern Hemisphere. Therefore, it can be concluded that the daytime VEWs may be influenced more significantly by the geographic than the magnetic latitudes. During nighttime, better symmetries of VEWs about the magnetic equator suggest that the VEWs are more 
dependent on magnetic latitudes. The latitudinal dependence of the VEWs during day and night agrees with the indication of Miller et al. (1997) for the meridional equivalent winds.

\subsection{The local time and solar activity variation}

To further understand the latitudinal dependence of VEWs, Figs. 3 and 4 depict a snapshot of VEWs at particular local times during night and day at two solar activity levels. We do not discuss the VEWs during sunset and sunrise hours to avoid the possible uncertainty due to the rapid change in ionospheric processes (Titheridge, 1995a).

At higher latitudes, the nighttime VEWs magnitudes are relatively larger after midnight, while the daytime ones are greater before midday at both solar minimum and maximum (Figs. 3 and 4). At the same time, the tendency of VEWs increasing with latitude at higher latitudes (the higher the latitude, the larger the magnitudes of the VEWs, or a maximum at the highest latitude as far as the latitude are concerned in present work) also appears at most post-midnight hours and hours before midday. But the VEWs do not simply enhance in magnitude with latitude at higher latitudes. The latitudinal dependence of VEWs has two prevailing trends. In addition to the one of a maximum at the highest latitudes, the VEWs also show an apparent feature of a mid-latitude maximum, namely strongest at the mid-latitudes at both hemispheres, mostly between about $30^{\circ}-40^{\circ}$. After midday and before midnight, the second latitudinal trend appears with much more frequency than the first one, just in contrast with the periods when relatively stronger VEWs appear, except during daytime in winter solstice.

An inverse relationship between the VEWs and the solar activity is evident during both daytime and nighttime, similar to the results over Wuhan (Liu et al., 2003c) while different from the meridional winds predicted by the HWM model (Hagan, 1993; Buonsanto and Witasse, 1999). However, the latitudinal trend of VEWs is significantly dependent on season, and relatively less dependent on local time and solar activity. During solstice periods either of the two trends (a maximum at the highest latitude (MH) and a mid-latitude maximum (MM)) dominates both by day and at night at whatever solar activity level, while the latitudinal trend is very complex during equinox periods, changing with local time, solar activity and hemisphere (Figs. 3 and 4). The dependences of the latitudinal trend on hemisphere, local time, season, and solar activity are described in detail by Table 2. Compared to the nighttime trend, the daytime one has nearly opposite dependences on season during solstice periods.

To sum up, the mid-latitude maximum trend (MM) appears at a considered part of local hours during nighttime and by day in both hemispheres at whatever solar activity level (Table 2). It may be explained in part by the effect of the magnetic inclination. The most valid contribution of neutral meridional winds to VEWs lies at lower mid-latitude (near magnetic $23^{\circ}$ ), where the dip angle equals $45^{\circ}$, although the magnitudes of neutral meridional winds may be greatest at the highest latitudes, as predicted at midnight in the North- ern Hemisphere and at noon in the Southern Hemisphere by the HWM90 model (Miller et al., 1997). A mid-latitude maximum trend of meridional winds is also the possible reason, as predicted at midnight in the Southern Hemisphere and at noon in the Northern Hemisphere by HWM90 model (Miller et al., 1997). Given the dip angle, the latitudinal trend of a maximum at the highest latitude for VEWs indicates a much larger latitudinal gradient of meridional winds.

\subsection{The latitudinal gradient of VEWs}

Twelve stations with a magnetic latitude interval of about $4^{\circ}-16^{\circ}$ are singled out to derive the latitudinal gradient of VEWs. The gradients are attained from the ratio of $\Delta(V E W s) / \Delta$ (latitude) and the final results are from a polynomial fit of five degree. The relatively larger latitude interval between Vanimo (Magnetic $12.1^{\circ} \mathrm{S}$ ) and Townsville (Magnetic $28.4^{\circ} \mathrm{S}$ ) may introduce some uncertainty. To see clearly the regulation of the magnetic inclination on the VEWs, the related magnetic inclination angles are used as the label of abscissa axis rather than the magnetic latitudes. For higher latitudes, if the electric field drifts are insignificant and the relationship between the dip $(I)$ and the magnetic latitude $(\varphi)$ are assumed astan $I=2 \tan \varphi$, then the latitudinal gradient of VEWs can be estimated as follows:

$$
\begin{aligned}
& \frac{d(V E W s)}{d \varphi}=\frac{\partial U}{\partial \varphi} \sin (2 I) \\
& +U\left[0.75 \cos ^{2}(2 I)+1.25 \cos (2 I)\right],
\end{aligned}
$$

where $U$ is the meridional winds; $I$ is the magnetic dip between about $34^{\circ}-75^{\circ}$ in both hemispheres and $\varphi$ is the magnetic latitude between about $51^{\circ} \mathrm{S}-51^{\circ} \mathrm{N}$. In the right side of Eq. (3), the coefficients of the second term $0.75 \cos ^{2}(2 I)+1.25 \cos (2 I)$ decrease from about 0.52 to -0.52 with the dip angles at both hemispheres.

Figure 5 depicts the derived results in March, September, June and December for hours near noon and midnight. A positive (negative) gradient means an increase (decrease) pattern of VEWs with latitudes. The maximum gradients tend to appear at dip angles near $45^{\circ}$, with magnitudes varying between $1.0-2.6 \mathrm{~m} / \mathrm{s}$ per latitude degree near midday at solar minimum and typically about $2.0 \mathrm{~m} / \mathrm{s}$ per latitude degree at night. These gradients of VEWs indicate the same magnitudes of the meridional wind gradients, which are consistent with the results for diurnal amplitude of meridional winds $(1 \mathrm{~m} / \mathrm{s}$ per degree of latitudes) in June, 1987 (Miller et al., 1993). However, strong gradients appear around midnight at southern higher mid-latitudes $\left(I \approx 70^{\circ}\right)$ during all seasons in solar maximum and during December in solar minimum, and the most significant value can reach about $3 \mathrm{~m} / \mathrm{s}$ per latitude degree in March and June, indicating very strong meridional gradients (see Eq. (3)). Similarly, the strong meridional gradients have been reported by Salah et al. (1987) between Fritz Peak, Colorado (39.9 $\mathrm{N}, 105.5^{\circ} \mathrm{W}$ ) and Millstone Hill $\left(42.6^{\circ} \mathrm{N}, 71.5^{\circ} \mathrm{W}\right)$ on $26-28$ June 1984 . The recent climatologic study at Millstone Hill (Emmert et al., 2003) also shows 


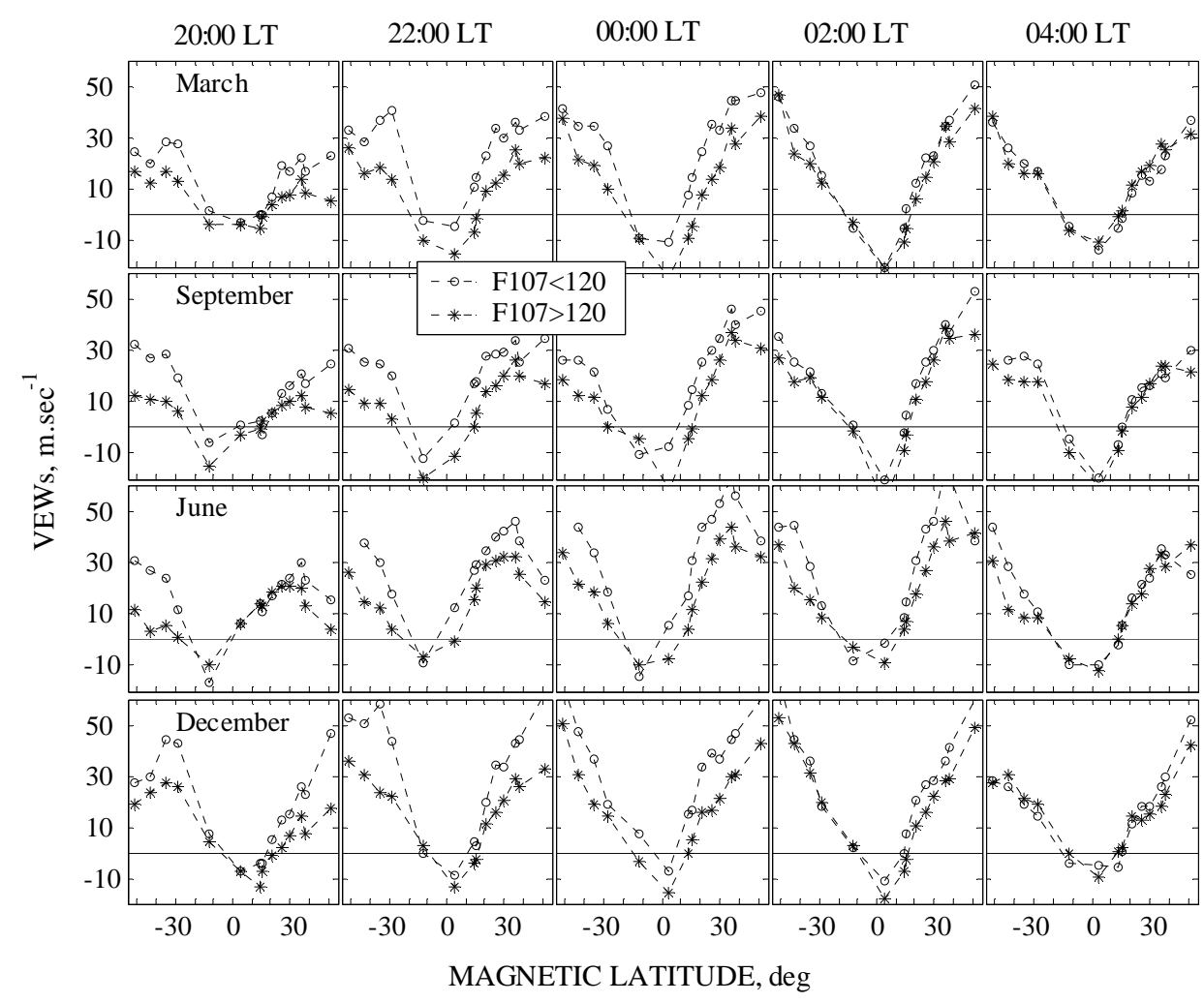

Fig. 3. Local time and solar activity variations of the vertical equivalent winds (VEWs) for all latitudes at night from 20:00 LT to 04:00 LT. The first to the last panels represent March equinox, September equinox, June solstice and December solstice, respectively. The lines with cycles and asterisks present VEWs of solar minimum and solar maximum, respectively. Positive upward.

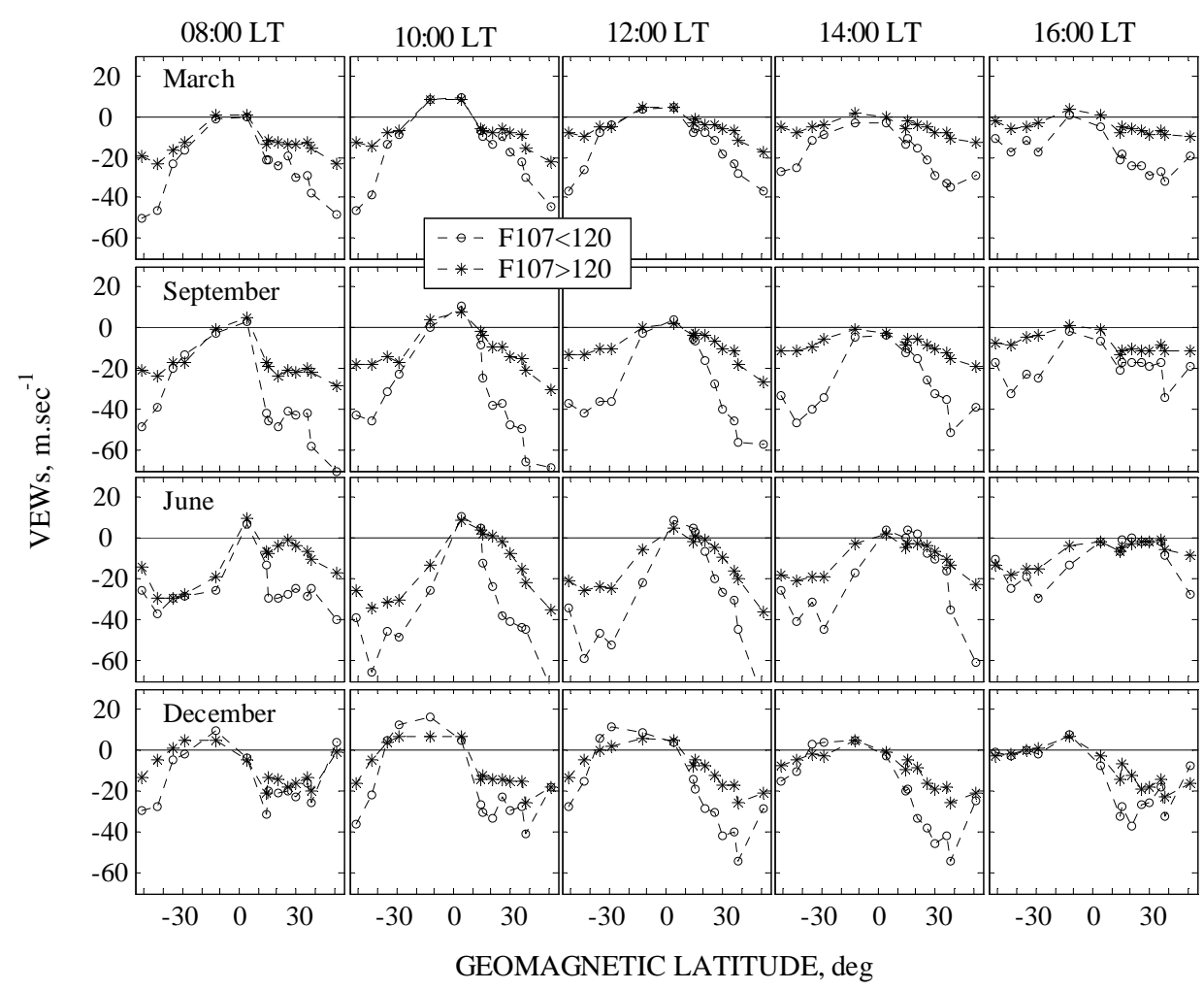

Fig. 4. Same as Fig. 3, but for daytime hours (08:00-16:00 LT). Positive upward. 
Table 2. The dependence of the two latitudinal trend on hemisphere, local time, season and solar activity*.

\begin{tabular}{|c|c|c|c|c|}
\hline \multirow[t]{2}{*}{ Season } & \multicolumn{2}{|c|}{ Night } & \multicolumn{2}{|c|}{ Day } \\
\hline & $\mathrm{F} 107<120$ & $\mathrm{~F} 107>120$ & $\mathrm{~F} 107<120$ & $\mathrm{~F} 107>120$ \\
\hline Summer & $\begin{array}{l}\mathrm{MM}(\mathrm{N}) \\
\mathrm{MM}(\mathrm{S}, \text { before 0:00 LT }) \\
\mathrm{MH}(\mathrm{S}, \text { after 0:00 LT })\end{array}$ & Same as the left & $\mathrm{MH}$ & MH \\
\hline Winter & MH & MH & MM & MM \\
\hline September & MH & $\begin{array}{l}\mathrm{MM}(\mathrm{N}) \\
\mathrm{MH}(\mathrm{S})\end{array}$ & $\begin{array}{l}\mathrm{MH}(\mathrm{N}) \\
\mathrm{MM}(\mathrm{S})\end{array}$ & $\begin{array}{l}\text { MH (a.m.) } \\
\text { MM (p.m.) }\end{array}$ \\
\hline March & $\begin{array}{l}\text { depends on local time } \\
\text { and hemisphere }\end{array}$ & $\begin{array}{l}\text { depends on local time } \\
\text { and hemisphere }\end{array}$ & $\begin{array}{l}\text { MH (a.m.) } \\
\text { MM (p.m.) }\end{array}$ & $\begin{array}{l}\text { MH (N) } \\
\text { MM (S) }\end{array}$ \\
\hline
\end{tabular}

* MM and MH stand for the trends of a mid-latitude maximum and a maximum at the highest latitude, respectively.

$N$ and $S$ note in the Northern and Southern Hemisphere, respectively. a.m. and p.m. denote local times before and after midday, respectively.

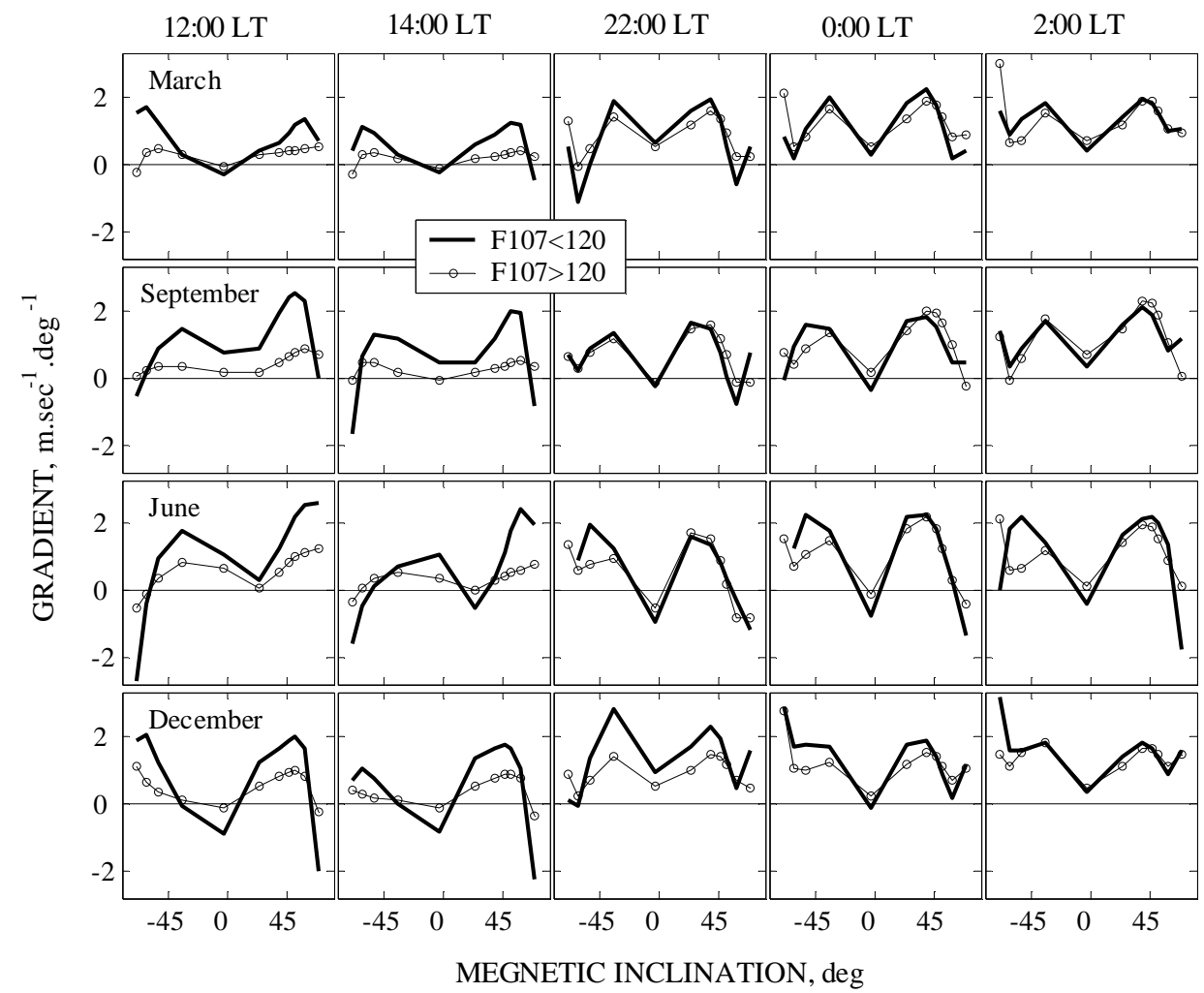

Fig. 5. The magnetic latitudinal gradient of the VEWs near noon and midnight hours for all seasons at solar minimum and solar maximum.

very significant latitudinal gradients for meridional winds at all seasons, especially during equinox periods at solar minimum. The strong positive latitudinal gradients for VEWs and meridional winds at southern higher mid-latitudes suggest an influence by the high-latitude magnetospheric convection (Hagan, 1993; Emmert et al., 2003). Strong gradients also appear at higher mid-latitudes during summer solstice periods near noon.

The latitudinal gradients of VEWs depend on solar activity more significantly by day than during nighttime (Fig. 5), and they can well reflect the latitudinal trend of VEWs. In agreement with the trend of a mid-latitude maximum for VEWs, 
Table 3. Diurnal mean velocity $(\mathrm{m} / \mathrm{s})$ of equivalent winds, and their diurnal $(\mathrm{D})$, semidiurnal $(\mathrm{S})$, and terdiurnal $(\mathrm{T})$ amplitude $(\mathrm{m} / \mathrm{s})$ and phase (UT, hour) for solstice periods of June and December.

\begin{tabular}{|c|c|c|c|c|c|c|c|c|}
\hline \multirow[t]{2}{*}{ Station } & \multirow[t]{2}{*}{ Month } & \multicolumn{4}{|c|}{ Amplitude } & \multicolumn{3}{|c|}{ Phase } \\
\hline & & Mean & $\mathrm{D}$ & $\mathrm{S}$ & $\mathrm{T}$ & $\mathrm{D}$ & $\mathrm{S}$ & $\mathrm{T}$ \\
\hline Hobart & $\begin{array}{l}\text { June } \\
\text { December }\end{array}$ & - & $\overline{44.4}$ & $\begin{array}{l}- \\
17.1\end{array}$ & - & $\frac{-}{13.2}$ & $-\overline{6.4}$ & - \\
\hline Canberra & $\begin{array}{l}\text { June } \\
\text { December }\end{array}$ & $\begin{array}{r}0.8 \\
10.5\end{array}$ & $\begin{array}{l}51.1 \\
34.2\end{array}$ & $\begin{array}{r}7.8 \\
10.5\end{array}$ & $\begin{array}{l}3.4 \\
3.9\end{array}$ & $\begin{array}{l}13.9 \\
13.4\end{array}$ & $\begin{array}{r}12.2 \\
5.5\end{array}$ & $\begin{array}{l}9.4 \\
4.7\end{array}$ \\
\hline Brisbane & $\begin{array}{l}\text { June } \\
\text { December }\end{array}$ & $\begin{array}{r}-0.3 \\
17.3\end{array}$ & $\begin{array}{l}38.5 \\
25.6\end{array}$ & $\begin{array}{r}4.0 \\
12.3\end{array}$ & $\begin{array}{l}3.0 \\
6.4\end{array}$ & $\begin{array}{l}13.6 \\
12.7\end{array}$ & $\begin{array}{r}13.0 \\
2.0\end{array}$ & $\begin{array}{l}8.8 \\
5.6\end{array}$ \\
\hline Townsville & $\begin{array}{l}\text { June } \\
\text { December }\end{array}$ & $\begin{array}{r}-8.9 \\
10.3\end{array}$ & $\begin{array}{l}36.1 \\
12.2\end{array}$ & $\begin{array}{l}5.8 \\
7.4\end{array}$ & $\begin{array}{l}3.6 \\
9.7\end{array}$ & $\begin{array}{l}14.2 \\
12.5\end{array}$ & $\begin{array}{l}15.0 \\
23.6\end{array}$ & $\begin{array}{r}10.5 \\
5.3\end{array}$ \\
\hline Vanimo & $\begin{array}{l}\text { June } \\
\text { December }\end{array}$ & $\begin{array}{r}-16.2 \\
5.6\end{array}$ & $\begin{array}{l}8.2 \\
5.4\end{array}$ & $\begin{array}{l}5.7 \\
3.7\end{array}$ & $\begin{array}{l}1.4 \\
7.4\end{array}$ & $\begin{array}{r}14.1 \\
5.1\end{array}$ & $\begin{array}{r}10.8 \\
2.4\end{array}$ & $\begin{array}{l}9.1 \\
1.9\end{array}$ \\
\hline Manila & $\begin{array}{l}\text { June } \\
\text { December }\end{array}$ & $\begin{array}{r}3.2 \\
-5.6\end{array}$ & $\begin{array}{l}2.6 \\
6.2\end{array}$ & $\begin{array}{r}10.0 \\
2.7\end{array}$ & $\begin{array}{l}1.4 \\
2.4\end{array}$ & $\begin{array}{l}9.1 \\
2.7\end{array}$ & $\begin{array}{l}4.8 \\
4.5\end{array}$ & $\begin{array}{l}21.9 \\
12.2\end{array}$ \\
\hline Taipei & $\begin{array}{l}\text { June } \\
\text { December }\end{array}$ & $\begin{array}{r}3.9 \\
-11.0\end{array}$ & $\begin{array}{l}12.2 \\
16.2\end{array}$ & $\begin{array}{r}12.4 \\
7.6\end{array}$ & $\begin{array}{l}3.5 \\
4.7\end{array}$ & $\begin{array}{l}13.6 \\
15.6\end{array}$ & $\begin{array}{l}6.1 \\
7.9\end{array}$ & $\begin{array}{l}12.1 \\
14.0\end{array}$ \\
\hline Okinawa & $\begin{array}{l}\text { June } \\
\text { December }\end{array}$ & $\begin{array}{r}3.0 \\
-10.2\end{array}$ & $\begin{array}{l}17.8 \\
20.5\end{array}$ & $\begin{array}{r}13.7 \\
4.5\end{array}$ & $\begin{array}{l}4.6 \\
5.6\end{array}$ & $\begin{array}{l}13.2 \\
15.9\end{array}$ & $\begin{array}{l}6.9 \\
8.0\end{array}$ & $\begin{array}{l}11.0 \\
13.8\end{array}$ \\
\hline Yamagawa & $\begin{array}{l}\text { June } \\
\text { December }\end{array}$ & $\begin{array}{r}6.6 \\
-4.5\end{array}$ & $\begin{array}{l}25.3 \\
32.3\end{array}$ & $\begin{array}{r}11.9 \\
4.1\end{array}$ & $\begin{array}{l}4.4 \\
4.3\end{array}$ & $\begin{array}{l}13.2 \\
15.9\end{array}$ & $\begin{array}{l}6.9 \\
8.0\end{array}$ & $\begin{array}{l}11.0 \\
13.8\end{array}$ \\
\hline Kokubunji & $\begin{array}{l}\text { June } \\
\text { December }\end{array}$ & $\begin{array}{r}7.8 \\
-2.1\end{array}$ & $\begin{array}{l}33.6 \\
35.7\end{array}$ & $\begin{array}{l}9.8 \\
4.0\end{array}$ & $\begin{array}{l}2.9 \\
2.1\end{array}$ & $\begin{array}{l}14.3 \\
15.3\end{array}$ & $\begin{array}{l}9.3 \\
3.7\end{array}$ & $\begin{array}{r}13.1 \\
8.6\end{array}$ \\
\hline Akita & $\begin{array}{l}\text { June } \\
\text { December }\end{array}$ & $\begin{array}{r}10.8 \\
0.2\end{array}$ & $\begin{array}{l}36.8 \\
36.7\end{array}$ & $\begin{array}{l}7.8 \\
2.1\end{array}$ & $\begin{array}{l}2.4 \\
1.4\end{array}$ & $\begin{array}{l}14.5 \\
15.1\end{array}$ & $\begin{array}{l}9.5 \\
1.9\end{array}$ & $\begin{array}{r}15.2 \\
5.2\end{array}$ \\
\hline Wakkanai & $\begin{array}{l}\text { June } \\
\text { December }\end{array}$ & $\begin{array}{r}11.2 \\
1.9\end{array}$ & $\begin{array}{l}43.1 \\
39.1\end{array}$ & $\begin{array}{r}10.2 \\
1.2\end{array}$ & $\begin{array}{l}0.2 \\
1.4\end{array}$ & $\begin{array}{l}14.6 \\
15.1\end{array}$ & $\begin{array}{l}10.6 \\
23.1\end{array}$ & $\begin{array}{r}21.4 \\
4.0\end{array}$ \\
\hline Khabarovsk & $\begin{array}{l}\text { June } \\
\text { December }\end{array}$ & $\begin{array}{r}6.9 \\
-4.9\end{array}$ & $\begin{array}{l}50.4 \\
55.7\end{array}$ & $\begin{array}{r}11.2 \\
5.1\end{array}$ & $\begin{array}{l}3.2 \\
2.9\end{array}$ & $\begin{array}{l}15.0 \\
15.2\end{array}$ & $\begin{array}{l}11.7 \\
20.3\end{array}$ & $\begin{array}{l}1.6 \\
7.5\end{array}$ \\
\hline Yakutsk & $\begin{array}{l}\text { June } \\
\text { December }\end{array}$ & $\begin{array}{r}-8.3 \\
18.9\end{array}$ & $\begin{array}{l}54.7 \\
46.3\end{array}$ & $\begin{array}{r}15.4 \\
3.4\end{array}$ & $\begin{array}{l}2.5 \\
3.5\end{array}$ & $\begin{array}{l}15.0 \\
15.4\end{array}$ & $\begin{array}{l}15.8 \\
20.3\end{array}$ & $\begin{array}{r}21.5 \\
9.9\end{array}$ \\
\hline
\end{tabular}

the transition from positive to negative gradient (if exist) generally lies near dip angles of about $60^{\circ}$. The always positive gradients at higher latitudes represent the other latitudinal trend of VEWs, a maximum at the highest latitudes. At night, the latitudinal gradients are generally equal at solar maximum and minimum, except that they are a little smaller at southern higher latitudes at solar minimum. Apparent negative gradients appear at northern higher mid-latitudes in summer solstice, in agreement with the obvious latitudinal trend of a mid-latitude maximum of VEWs. The apparent features during daytime are that the gradients at higher mid-latitudes are significantly positive in summer solstice and negative in winter solstice at solar minimum. The features are similar at solar maximum while the latitudinal gradients are much smaller. In addition, the gradients tend to be smaller in September and March at both hemispheres during hours between 12:00-14:00 LT, consistent with small magnitudes of VEWs (Fig. 4).

\subsection{Tidal analysis}

Except for June and September at Hobart, the data at fourteen stations are used to derive the monthly mean velocities of VEWs and to investigate the first three tidal components with a least-square harmonic analysis, which has been used for investigating the seasonal variations of VEWs over Wuhan 
(Liu et al., 2003a), as follows:

$W(t)=W_{0}+\sum_{n=1}^{3} W_{n} \cos \left(n \omega t-\Phi_{n}\right)+l(e)$,

where $n$ is the order of tidal components, $W_{n}$ and $\Phi_{n}$ is the amplitude and initial phase of the $\mathrm{n}$-th order component, respectively; $\omega=2 \pi / 24$, the diurnal frequency. $W_{0}$ is the diurnal mean or the prevailing component of VEWs; $l(e)$ is the error term.

To learn more about the behavior of VEWs during the solstice periods, we take the VEWs at solar minimum as examples and the results are listed in Table 3. The mean velocities of VEWs are generally positive in summer solstice (northern June and southern December) and negative or small positive in winter solstice, in agreement with the results of meridional winds (Buonsanto, 1990; Buonsanto and Witasse, 1999; Foppiano et al., 2003). It suggests net flows transfer from the summer to the winter hemisphere. But it differs from the results of Igi et al. (1999) that the diurnal mean of meridional equivalent winds at Kokubunji is most strongly poleward in June and most strongly equatorward in November. There is also an exception at Yakutsk $\left(129.6^{\circ} \mathrm{E}, 62.0^{\circ} \mathrm{N}\right.$, Magnetic $51.5^{\circ} \mathrm{N}$ ), where the relationship between summer and winter mean is opposite. This abnormity may be due to the proximity of Yakutsk to the polar region. Moreover, no clear latitudinal dependence of diurnal mean is found.

The diurnal amplitudes generally increase with latitude at both hemispheres (Table 3), in agreement with those of the meridional winds for June, 1987 (Miller et al., 1993). For higher latitudes, the diurnal phases tend to be constant, varying between $13.2 \mathrm{~h}$ and $15.9 \mathrm{~h}$ (UT) at the Northern Hemisphere and between $12.5 \mathrm{~h}$ and $14.1 \mathrm{~h}$ (UT) at the Southern Hemisphere. Miller et al. (1993) included more stations at other longitude sectors and their results of the averaged diurnal phases are a little advanced, nearly $13.3 \mathrm{~h}$ and $12.0 \mathrm{~h}$ in the Northern and Southern Hemisphere, respectively. As shown in Table 3, diurnal amplitudes are much higher in winter than in summer solstice months at the Southern Hemisphere, similar to the results of three higher mid-latitude stations in the Southern Hemisphere (Foppiano et al., 2003) at solar minimum, while they are comparable at the Northern Hemisphere. The semidiurnal and terdiurnal amplitudes are relatively insignificant, except at equatorial and low latitudes, where the tidal amplitudes are small. At higher latitudes, the diurnal amplitudes are larger than the semidiurnal amplitudes for all seasons. This is also similar to the results of Foppiano et al. (2003). At low latitudes near the magnetic equator, the semidiurnal and terdiurnal amplitudes are considerable and even larger than the diurnal ones (e.g. at Manila and Vanimo). Similarly, the significant semidiurnal amplitude is also reported over Wuhan (Liu et al., 2003a). Therefore, the relative importance between major tidal amplitudes are different between low and higher latitudes, which also confirms an considerable difference between these two latitudinal ranges, as shown in Figs. 1 and 2.

\section{Comparison and discussions}

\subsection{Comparison with the prediction of empirical models}

To validate the parameters used in the present work and to see clear the major dynamical control of VEWs, Figs. 6a-6d exhibit a detailed comparison of the VEWs with the similar components estimated from empirical models in March. The VEWs at Manila $\left(121.1^{\circ} \mathrm{E}, 14.7^{\circ} \mathrm{N}\right.$, Magnetic $\left.3.9^{\circ} \mathrm{N}\right)$ and Wakkanai $\left(141.7^{\circ} \mathrm{E}, 45.4^{\circ} \mathrm{N}\right.$, Magnetic $\left.35.8^{\circ} \mathrm{N}\right)$ are selected as samples for equatorial latitude and mid-latitude, respectively. The similar components are estimated from the lowand middle-latitude horizontal wind model HWM93 (Hedin et al., 1996) and the empirical electric field drift model for equatorial latitude (Scherliess and Fejer, 1999), including: (1) the vertical components of the electric field drifts (E Drifts) and of the meridional winds (HWM), and (2) the superposition of E Drifts and HWM, namely empirical equivalent winds (EEWs). The VEWs generally agree well with EEWs at these two sites, especially in the local time variation, though some discrepancies exist in magnitudes.

At Manila (Figs. 6b and 6d), the VEWs are in good agreement with EEWs at solar maximum and minimum, except that the VEWs are smaller in magnitude during daytime. Similar to previous results inferred from ionosonde observations at solar maximum (Fejer et al., 1989), the VEWs are about half of the EEWs in magnitudes of the prereversal enhancement at solar maximum (Fig. 6b). The prereversal velocity of VEWs is almost absent at solar minimum, which is consistent with EEWs.

From late evening to early morning hours $(\sim 19: 00$ 06:00 LT), the VEWs are in general agreement with the only contribution of electric field drifts (E Drifts). Differently, in many previous works, the electric field drifts are mostly derived from the time dependence of the h'F data, and those results are reported to be reliable only during sunset and evening hours (Bittencount and Abdu, 1981; Fejer et al., 1989). At present work, the difference in magnitudes of night VEWs and E Drifts may be induced by the effect the meridional winds. The longitudinal variation of the electric field drifts is another possible reason (Scherliess and Fejer, 1999). During daytime, the magnitude differences between the VEWs and E Drifts are larger than those between the VEWs and EEWs, which may also be explained by the possible longitude effect of the electric field drifts and the considerable contribution of neutral winds. The latter is predicted by the HWM93 model. At equatorial latitudes near the longitude sector in question, a simulation by Chan and Walker (1984) also predicted a strong transequatorial winds throughout the daytime. In additon, the dip angle at Manila is about $14^{\circ}$. However, the similar temporal variation tendency between the VEWs and E Drifts presents a major contribution of electric field drifts. Better agreements between the VEWs and E Drifts can be expected if the dip is smaller.

At Wakkanai, the VEWs approach the maximum smoothly at midnight and tend to have two peaks during daytime, an early daylight one and a late afternoon one (Figs. 6a and 6c), 

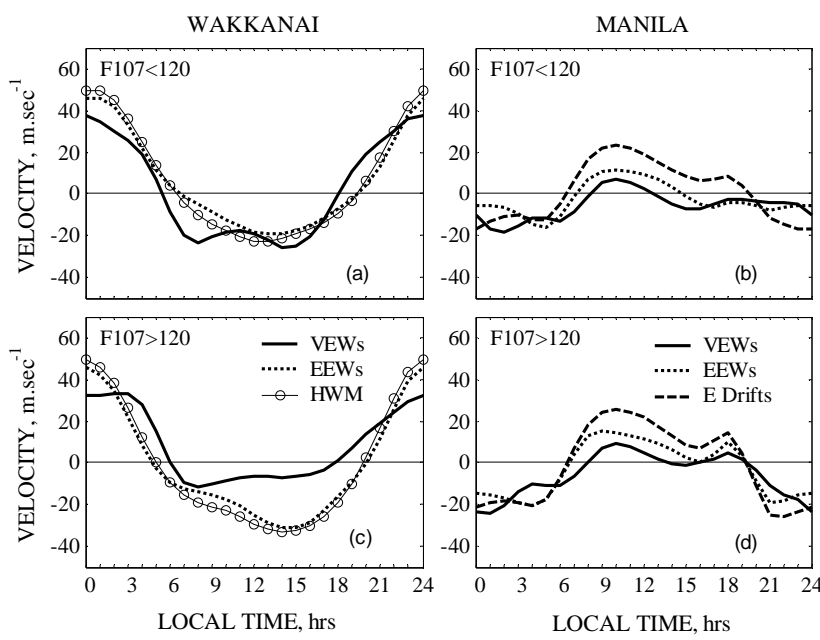

Fig. 6. The diurnal variations of VEWs (solid line) and some related components at Wakkanai $\left(139.5^{\circ} \mathrm{E}, 35.7^{\circ} \mathrm{N}\right)$ and Manila $\left(121.1^{\circ} \mathrm{E}\right.$, $14.7^{\circ} \mathrm{N}$, Magnetic $3.5^{\circ} \mathrm{N}$ ) during March equinox. (a) and (c): during solar minimum and maximum years at Manila, respectively. E Drifts (dashed) and HWM (solid lines with circled) note the vertical components of empirical electric field drifts and of meridional winds, respectively. EEWs notes the combination of E Drifts and HWM, namely empirical equivalent winds (dotted). The electric field drifts are estimated from the model of Scherliess and Fejer (1999) and the neutral meridional winds are from the HWM93 model (Hedin et al., 1996). Positive upward.

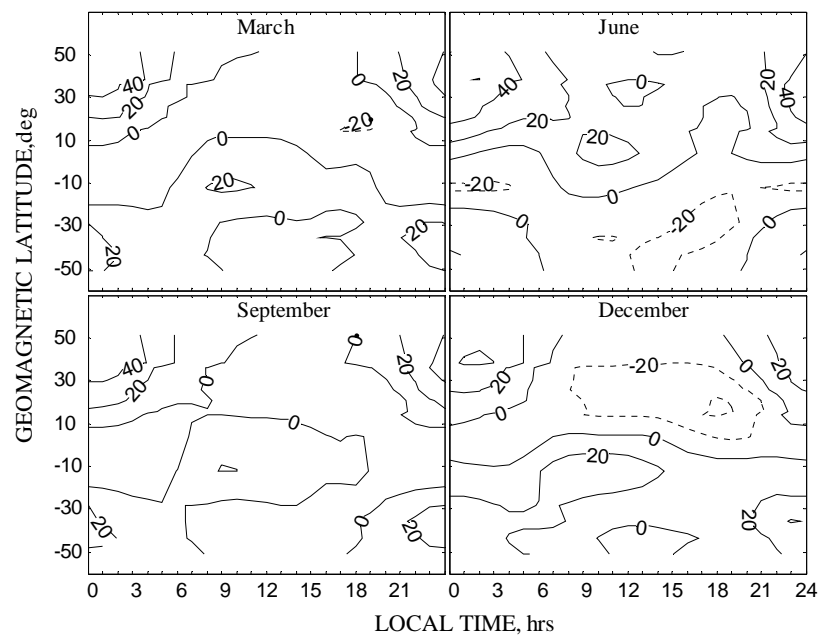

Fig. 7. The empirical equivalent winds (EEWs) at solar minimum estimated from the HWM93 model and the empirical electric field drift model by Scherliess and Fejer (1999). Positive upward.

very similar to the meridional winds derived from the MU radar measurements in Japan (Kawamura et al., 2000). In comparison with EEWs, the VEWs are more downward during sunrise period and upward during sunset period at solar minimum, while they are much smaller during daytime at solar maximum. These discrepancies are also very similar to the comparison by Kawamura et al. As expected, there is almost no difference between EEWs and the contribution of neutral components, HWM (Figs. 6a and 6c), which show that the electric field drifts contribute little to VEWs.

The two examples above show that the contribution of neutral components increases with latitudes. At the lower midlatitude station of Wuhan, the VEWs are also reported to be mostly driven by neutral winds and vary consistently with neutral components (Liu et al., 2003a, b). At lower latitudes, neither electric field drifts nor neutral meridional winds can dominate the VEWs and greater discrepancy between the VEWs and EEWs appears at some local times. Great discrepancy also appears at higher mid-latitudes (not present here). The possible reason may be the less reliability of the wind and electric field model at those respective latitudes.

Corresponding to Fig. 1, Fig. 7 presents the variation of the empirical equivalent winds (EEWs) at all analyzed stations during solar minimum years. The EEWs are similar to the VEWs in the Northern Hemisphere at night, while great discrepancy in magnitude appears by day. The EEWs are not approximately symmetrical about the magnetic equator. First, in equinoctial months, the approximate symmetry center of EEWs departs from the magnetic equator, locating at magnetic latitudes between $0^{\circ}-10^{\circ} \mathrm{S}$, and mostly near $10^{\circ} \mathrm{S}$. Second, during daytime, the flow in the summer hemisphere is almost upward. Finally, at night the EEWs are generally smaller by a magnitude of about $20 \mathrm{~m} / \mathrm{s}$ in the Southern Hemisphere than in the Northern Hemisphere. This may be partly attributed to poor predictions of HWM93 in the Southern Hemisphere because of a sparse database, which has already been pointed out by many authors (Titheridge, 1995b; Miller et al., 1997). Another reason may be that the empirical electric field drift model is less reliable beyond equatorial and low latitudes. In addition, the daytime EEWs are more significant than VEWs at equatorial and low latitudes in summer solstice, consistent with the comparison presented at Manila (Figs. 6b and 6d).

\subsection{Comparison with published results}

Compared to the meridional equivalent winds from Miller et al. (1997), the VEWs have similar latitudinal and solar activity dependences and symmetry about magnetic latitudes at night. But the daytime behavior has a great difference. The VEWs tend to have a reverse relationship with solar activity during daytime as they do at night, consistent with trends of the meridional winds based on the MU radar measurements in Japan (Kawamura et al., 2000). But Miller et al. predicted that the daytime equivalent winds increase with solar flux near winter solstice in the Southern Hemisphere and have no clear solar cycle dependence in the Northern Hemisphere. At northern higher latitudes, their results show that the equivalent winds increase rapidly with latitudes at noon. Differently, under the same conditions, the VEWs only increase quickly with latitudes in June and September, enhance slowly in other months, and diminish at higher mid-latitudes in winter solstice at both hemispheres (Fig. 4). The dependence of daytime winds on solar activity and latitude still needs further investigation. 


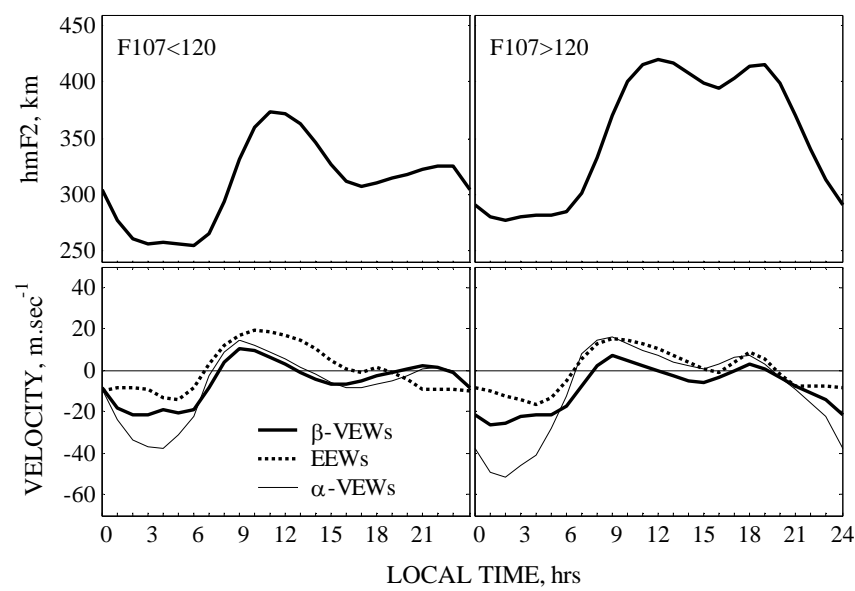

Fig. 8. The averaged F-layer peak height, $h m \mathrm{~F} 2$ (top panel), and corresponding equivalent winds based on Chapman- $\alpha$ ( $\alpha$-VEWs) and Chapman- $\beta$ ( $\beta$-VEWs) electron density profiles, and also empirical equivalent winds (EEWs) in September at two solar activity levels at Manila (bottom panel).

\subsection{The effect of assumed topside electron density}

The well-known electron density profiles of Chapman- $\alpha$ and Chapman- $\beta$ distribution represent two important ideal cases of the square-law formula loss processes and linear loss processes, respectively. The Chapman- $\alpha$ layer has been assumed to be a topside profile and successfully applied to derive meridional equivalent winds by servo techniques at higher latitudes (Risbeth, 1978; Buonsanto et al., 1990, 1997), and also adopted to derive VEWs over Wuhan $\left(114.4^{\circ} \mathrm{E}, 30.6^{\circ} \mathrm{N}\right.$, Magnetic $20^{\circ} \mathrm{N}$ ) with our method (Liu et al., 2003a, b, c). In this work, using either of the two profiles can lead to similar VEWs, except for a typical difference of $10 \mathrm{~m} / \mathrm{s}$ in magnitude. Under the same conditions, the difference using these two profiles generally appears at around midnight at low latitudes and near the sunrise and sunset period at higher latitudes when the $\mathrm{F}$ layer peak height is relatively low. The difference can reach $30 \mathrm{~m} / \mathrm{s}$ at low latitudes and $20 \mathrm{~m} / \mathrm{s}$ at higher mid-latitudes, appearing at September at solar maximum. Figure 8 shows the comparison of VEWs using Chapman- $\beta$ and Chapman- $\alpha$ distribution for the topside profiles ( $\beta$-VEWs and $\alpha$-VEWs, respectively) and the related averaged $h m \mathrm{~F} 2$ at Manila during September under two solar activity levels. In comparison with EEWs, the VEWs using Chapman- $\alpha$ distribution seem to greatly overestimate the nighttime VEWs, when the F2 layer peak height is relatively low, though having a good agreement with EEWs during the daytime at solar maximum. Under the assumption of Chapman- $\beta$ electron density distribution, our calculated equivalent winds have general agreements with empirical model prediction at their valid latitudes both at solar minimum and maximum (Figs. 6a-6d). A future work will try to use more reliable topside electron profiles and other parameters to improve the results, especially when chemical processes are important at relatively lower peak heights.

\section{Conclusions}

Based on the ionosonde measurements for more than two decades, the climatology of the vertical equivalent winds (VEWs) along the $120^{\circ}-150^{\circ} \mathrm{E}$ longitude sector is investigated with an emphasis on their latitudinal dependence. The VEWs are strongly dependent on magnetic latitude. The dependence of their latitudinal trends on local time, season and solar activity are also discussed in detail.

The features of VEWs have considerable differences between the lower and higher latitudes in their direction, magnitude and also the solar activity dependence, as well as the relative importance between the major tidal components. Besides the magnitudes of meridional winds and zonal electric field drifts, the magnetic dip modulates the relative contributions between the neutral and electric field components. The VEWs are more controlled by electric field at low latitudes and by neutral meridional winds at higher latitudes.

The basic latitudinal dependences of VEWs are their approximate symmetry about the magnetic equator and larger magnitudes at higher latitudes, with a maximum occurring at around magnetic mid-latitudes (about $30^{\circ}-40^{\circ}$ in a considerable percentage of local hours during daytime and nighttime). The extent of the symmetry is relatively better during equinox than solstice periods and at night than by day. During solstice periods, pronounced transequatorial meridional winds are indicated by the VEWs.

The latitudinal dependence of VEWs has two prevailing trends: one is a mid-latitude maximum and the other is a maximum at the highest latitude (the higher the latitude, the larger the magnitudes, as far as the latitudes are concerned in the present work). These two trends depend mainly on seasons while partly on local time and solar activity as well. The derived latitudinal gradient of VEWs reflects well the latitudinal dependence of the VEWs. The VEWs at southern higher mid-latitudes show very strong latitudinal gradient and indicate significant latitudinal gradient of meridional winds.

Our results are based on some assumptions similar to the servo method (Rishbeth et al., 1978), including an approximate topside profile of the electron density. The VEWs are compared with the corresponding components estimated from empirical models at both equatorial latitude and midlatitude in detail, where it is appropriate to apply the empirical models. The similar comparison is also carried out over an expanded latitudinal range. Moreover, our results are compared with related published results. General agreements, as well as some discrepancies, are found in the comparisons above. A more practical topside profile of the electron density may improve our results.

Acknowledgements. This research was supported by the National Natural Science Foundation of China $(40274054,40134020)$ and Important Basis Research Project of China (G2000078407). The codes of the MSIS, HWM93, and IRI90 models are provided by the World Data Center-A. The ionosonde data are from the published Ionospheric Digital database by the U.S. National Geophysics Data Center (NGDC) in Boulder, Colorado. 
Topical Editor U. Hoppe thanks S. Kawamura for his help in evaluating this paper.

\section{References}

Balan, N., Bailey, G. J., Moffett, R. J., Su, Y. Z., and Titheridge, J. E.: Modelling studies of the conjugate-hemisphere differences in ionospheric ionization at equatorial anomaly latitudes, J. Atoms. Terr. Phys., 57, 279-292, 1995.

Biondi, M. A., Sazykin, S. Y., Fejer, B. G., Meriwether, J. W., and Fesen, C. G.: Equatorial and low latitude thermospheric winds: Measured quiet time variation with season and solar flux from 1980 to 1990, J. Geophys. Res., 104, 17 091-17 106, 1999.

Bittencourt, J. A. and Abdu, M. A.: A theoretical comparison between apparent and real vertical ionization drift velocitys in the equatorial F region, J. Geophys. Res., 86, 2451-2434, 1981.

Buonsanto, M. J. and Titheridge, J. E.: Diurnal variations in the flux of ionisation above the F2 peak in the northern and Southern Hemispheres, J. Atoms. Terr. Phys., 49, 1093-1105, 1987.

Buonsanto, M. J.: Observed and calculated F2 peak height and derived meridional winds at mid-latitudes over a full solar cycle, J. Atoms. Terr. Phys., 52, 223-240, 1990.

Buonsanto, M. J., Starks, M. J., Titheridge, J. E., Richards, P. G., and Miller, K. L.: Comparison of techniques for derivation of neutral meridional winds from ionospheric data, J. Geophys. Res., 102, 14 477-14484, 1997.

Buonsanto, M. J. and Witasse, O. G.: An updated climatology of thermospheric neutral winds and $F$ region ion drifts above Millstone Hill, J. Geophys. Res., 104, 24 675-24 687, 1999.

Chan, H. F. and Walker, G. O.: Computer simulations of the ionospheric equatorial anomaly in East Asia for equinoctial, solar minimum conditions. Part II- results and discussion of wind effects, J. Atoms. Terr. Phys., 46, 1113-1120, 1984.

Dudency, J. R.: The accuracy of simple methods for determining the height of the maximum electron concentration of the F2-layer from scaled ionospheric characteristics, J. Atoms. Terr. Phys., 45, 629-640, 1983.

Emmert, J. E., Fejer, B. G., and Sipler, D. P.: Climatology and latitudinal gradients of quiet time thermospheric neutral winds over Millstone Hill from Fabry-Perot interferometer measurements, J. Geophys. Res., 108(A5), 1196, doi:10.1029/2002JA009765, 2003.

Fejer, B. G., de Paula, E. R., Bastista, I. S., Bonelli, E., and Woodman, R. F.: Equatorial F region vertical plasma drifts during solar Maxima, J. Geophys. Res., 94, 12 049-12 054, 1989.

Fejer, B. G., Emmert, J. T., and Sipler, D. P.: Climatology and storm time dependence of nighttime thermospheric neutral winds over Millstone Hill, J. Geophys. Res., 107(A5), 1052, doi:10.1029/ 2001JA000300, 2002.

Foppiano, A. J., Torres, X. A., Arriagada, M. A., and Flores, P. A.: Meridional thermospheric winds over the Antarctic Peninsula longitude sector, J. Atoms. Terr. Phys., 65, 305-314, 2003.

Hagan, M. E.: Quiet upper thermospheric winds over Millstone Hill between 1984 and 1990, J. Geophys. Res., 98, 3731-3739, 1993.

Hedin, A. E.: MSIS-86 thermospheric model, J. Geophys. Res., 92, 4649-4662, 1987.

Hedin, A. E., Fleming, E. L., Manson, A. H., Schmidlin, F. J., Avery, S. K., Clark, R. R., Franke, S. J., Fraser, G. J., Tsuda, T.,
Vial, F., and Vincent, R. A.: Empirical wind model for the upper, middle and lower atmosphere, J. Atmos. Terr. Phys., 58, 14211447, 1996.

Igi, S., Oliver, W. L., and Ogawa, T.: Solar cycle variations of the thermospheric meridional wind over Japan derived from measurements of $h m$ F2, J. Geophys. Res., 104, 22 427-22 431, 1999.

Karpachev, A. T. and Gasilov, N. A.: Zonal and meridional wind components derived from intercosmos-19 hmF2 measurements, Adv. Space Res., 27, 1245-1252, 2001.

Kawamura, S., Otsuka, Y., Zhang, S.-R., Fukao, S., and Oliver, W. L.: A climatology of middle and upper atmosphere radar observations of thermospheric winds, J. Geophys. Res., 105, $12777-$ $12788,2000$.

Liu, L., Luan, X., Wan, W., Lei, J., and Ning, B.: Seasonal behaviors of equivalent winds over wuhan derived from ionospheric data in 2000-2001, Adv. Space Res., 32, 1765-1770, 2003 a.

Liu, L., Luan, X., Wan, W., Ning, B., and Lei, J.: A new approach to the derivation of dynamic information from ionosonde measurements, Ann. Geophys., 21, 2185-2191, 2003 b.

Liu, L., Wan, W., Luan, X., Ning, B., and Lei, J.: Solar activity dependence of the effective winds derived from ionospheric data at Wuhan, Adv. Space Res, 32, 1719-1724, 2003c.

Miller, K. L., Richards, P. G., and Wu, H. Y.: A global-scale study of meridional winds and electron densities in the F-region during the Sundial campaign, Ann. Geophys., 11, 572-584, 1993.

Miller, K. L., Lemon, M., and Richards, P. G.: A meridional wind climatology from a fast model for the derivation of meridional winds from the height of the ionospheric F2 region, J. Atmos. Terr. Phys., 59, 1805-1822, 1997.

Oliver, W. L. and Salah, J. E.: The global thermospheric mapping study, J. Geophys. Res., 93, 4039-4059, 1988.

Pesnell, W. D., Omidvar, K., and Hoegy, W. R.: Momentum transfer collision frequency of O+-O, Geophys. Res. Lett., 20, 13431346, 1993.

Rishbeth, H.: The effect of winds on the ionospheric F2-peak, J. Atmos. Terr. Phys., 29, 225-238, 1967.

Rishbeth, H., Ganguly, S., and Walker, J. C. G.: Field-aligned and field-perpendicular velocities in the ionospheric F2 layer, J. Atmos. Terr. Phys., 40, 767-784, 1978.

Salah, J. E., Hernandez, G., Roble, R. G., and Emery, B. A.: Longitudinal and latitudinal dependences of the thermospheric winds from incoherent scatter radar and optical emission Doppler shift measurements, Ann. Geophys., 5, 359-362, 1987.

Scherliess, L. and Fejer, B. G.: Radar and satellite global equatorial F region vertical drift model, J. Geophys. Res., 104, 6829-6842, 1999.

Titheridge, T. E.: The calculation of neutral winds from ionospheric data, J. Atmos. Terr. Phys., 57, 1015-1036, 1995a.

Titheridge, J. E.: Winds in the ionosphere-A review, J. Atmos. Terr. Phys., 57, 1681-1714, 1995b.

Wickwar, V. B.: Global thermospheric studies of neutral dynamics using incoherent-scatter radars, Adv. Space Res., 9, 87-102, 1989.

Zhang, S.-R., Huang, X.-Y. and Su, Y.-Z.: Monthly average behavior and oscillation of derived ionospheric drifts, Report UAG104, WDC-A for STP, NOAA, Boulder Co., January 1995.

Zhang, S.-R., Oliver, W. L., and Fukao, S.: MU Radar Ion Drift Model, Adv. Space Res., 27, 115-120, 2001. 